American Journal of Pharmaceutical Education 2019; 83 (7) Article 7106.

\title{
BRIEF
}

\section{Training Student Pharmacists in Medication Dispensing and Checking Within a High-Fidelity Clinical Environment}

\author{
Hamde Nazar, PhD, ${ }^{\mathrm{a}}$ Laura Lindsey, PhD, ${ }^{\mathrm{a}}$ Julie Fletcher, BPharm, ${ }^{\mathrm{b}}$ Louise Rook, ${ }^{\mathrm{b}}$ Adam Todd, PhD, ${ }^{\mathrm{a}}$ \\ Andrew Husband, DProf ${ }^{\text {a }}$ \\ ${ }^{a}$ School of Pharmacy, Newcastle University, Newcastle upon Tyne, United Kingdom \\ ${ }^{\mathrm{b}}$ Newcastle-upon-Tyne Hospitals NHS Trust, Newcastle, United Kingdom \\ Submitted April 10, 2018; accepted September 21, 2018; published September 2019.
}

Objective. To describe the implementation of and student pharmacist experience with high-fidelity training in medication dispensing and clinical checking processes and procedures.

Methods. An actual dispensary in a large teaching hospital was used as the setting in which to provide undergraduate student pharmacists the opportunity to develop skills and knowledge regarding the process and procedures of medication dispensing and clinical checking. The sessions were facilitated by a member of the hospital pharmacy team and overseen by a faculty member. Students were required to conduct legal and clinical checks and process anonymized hospital prescriptions. Students recorded their experiences in their professional portfolio as blog entries, which were then discussed with academic staff members on a biweekly basis. Content analysis of the blogs was conducted to investigate the student experience.

Results. Forty-eight students attended 30 hours of dispensing sessions over a 20 -week period from September to April. Content analysis of 102 blog entries demonstrated students reporting observations and experiences which mapped to the three components of communities of practice: the domain of pharmacy practice, the working dynamics of a community of professionals within the workplace, and the commonality of practice and shared repertoire of resources.

Conclusion. The high-fidelity teaching of students about the dispensing and checking process in an actual dispensary environment supports student pharmacists' knowledge and skills development. The work-based nature of this approach also provides experiential learning opportunities for students to observe and participate in the professional community of practice.

Keywords: dispensing, work-based learning, simulation teaching

\section{INTRODUCTION}

In recent years, the profession of pharmacy has evolved dramatically, with many pharmacists now working within multidisciplinary teams and undertaking patient-focused, specialist roles. Despite this shift, there are still core skills and competencies that remain crucial to the role of a qualified pharmacist, for example, the verification of prescription orders and dispensing of medications. As such, the regulatory body for pharmacy in the United Kingdom, the General Pharmaceutical Council, stipulates that pharmacy schools must ensure that undergraduate pharmacy programs include teaching and learning opportunities for students to develop the knowledge

Corresponding Author: Hamde Nazar, School of Pharmacy, Newcastle University, King George VI Bldg., King's Rd., Newcastle upon Tyne NE1 7RU, UK. Tel: 01912082361. E-mail: Hamde.nazar@newcastle.ac.uk and skills involved in dispensing medications and verifying orders. ${ }^{1}$ As a competency, dispensing and verifying medication orders requires the application of specialist knowledge of drug action and therapeutic use, practical and behavioral competence and judgement that is underpinned by appropriate professional ethics and values. ${ }^{2,3}$ The integrated nature of knowledge, skills, and behavior can be developed across professional activities and decision-making opportunities that students encounter during undergraduate pharmacy programs in the United Kingdom. However, this will potentially only achieve the learning of component parts and preliminary development of ethical and professional values. Consolidation for higher-level skills are usually acquired through continued professional practice following graduation. ${ }^{4}$

Pharmacy schools, in an effort to maximize the development of competency and professional identity in students despite the limited work-based learning 


\section{American Journal of Pharmaceutical Education 2019; 83 (7) Article 7106.}

opportunities available for them, ${ }^{5}$ can explore using simulation strategies wherever possible. Within the practice of dispensing, simulation can range from low-fidelity mock patient prescriptions in a classroom setting, to higher-fidelity activities, as exemplified by the recently reported simulated learning environment, MyDispense (https://info.mydispense.monash.edu). ${ }^{4}$ This online, authentic learning platform allows students the opportunity to engage with the entire process of dispensing while providing interactive explanations and feedback on performance to them. ${ }^{4}$ This approach can be described as being "high" in psychological fidelity (ie, high fidelity) if users temporarily suspend disbelief and interact as they would in the real world. The other two dimensions of fidelity are the equipment and the environment. ${ }^{6}$ Equipment fidelity relates to the similarity in appearance and feel of the simulator, while environment fidelity considers the extent to which the simulator duplicates motion cues, visual cues, and other sensory information from the task environment. $^{7}$ One approach that aims to achieve high-fidelity in all three dimensions would be to provide or tailor work-based learning to ensure students are able to gain experience and competence in this aspect of pharmacy. However, opportunities to provide such practical, experiential learning are challenging and limited, because of increasing demand and finite student support resources. ${ }^{8}$ Work-based learning is recognized to allow workers to learn by collective action and skill as well as by rational thought as it blends theory with practice. ${ }^{9}$ Work-based learning also provides the opportunity for the development of a community of practice. Lave and Wenger describe this using three specific components: where workers evolve and come together united (the community) in a common enterprise (the domain) to develop a shared history, repertoire of values, beliefs, ways of talking and doing things (the practice). ${ }^{10,11}$

In this paper, we describe the design and assessment of an innovative approach to deliver dispensing and clinical checking education in a live hospital environment (a setting with high environment, equipment, and psychological fidelity). The goal of this strategy was to enhance knowledge transfer and usability in practical situations and provide students opportunities to develop professional competence, values, and behaviors toward upholding patient safety. This combination of goals is challenging, but careful configuration of the three dimensions of fidelity of the environment can facilitate a successful experience. ${ }^{7}$

\section{METHODS}

In August 2017, the Master of Pharmacy (MPharm) academic team at the School of Pharmacy, Newcastle
University, United Kingdom, undertook an annual review of teaching, learning, and assessment within the program. The MPharm is an undergraduate, Master's degree program, taught in line with the Quality Assurance Agency (QAA), Framework for Higher Education Qualifications (FHEQ) Level 7 learning outcomes. It is the only undergraduate route to registration as a pharmacist with the General Pharmaceutical Council.

Instruction in medication dispensing and clinical checking is delivered in stage 2 (year 2) of the fully professionally accredited MPharm program. This educational provision had previously been managed in a medium-fidelity simulated dispensary (a setting with low environment fidelity) with a mixture of placebo (specifically for controlled drugs) or drug-filled medication boxes and bottles (a setting with high equipment fidelity). Students were provided with a range of mock prescriptions; tasked to assess the prescriptions for validity, legality, and clinical appropriateness; and then instructed to resolve any problems identified before dispensing the appropriate medication. Each teaching session was facilitated by a pharmacy technician (high psychological fidelity). In the United Kingdom, hospital dispensary environments are primarily staffed by technicians and technical assistants. Pharmacists work on the hospital wards and clinics conducting, among other things, the clinical checking of prescriptions prior to dispensing. Technicians have primary responsibility for the technical dispensing process once a prescription has been clinically validated by a pharmacist. Thus, the use of a technician in these university-based sessions more closely aligned with the experience of real-life practice. This previous teaching strategy posed its own challenges, which have previously been reported by McDowell and colleagues, and include difficulty in accommodating large teaching classes as well as high operational costs in terms of space, staffing, provision, and maintenance of current medicines stock. ${ }^{4}$

The School of Pharmacy at Newcastle University, UK, has two campuses and benefits from the sharing of some estate (buildings) and has close links with a major teaching hospital, the Royal Victoria Infirmary (RVI), which forms part of the Newcastle-upon-Tyne Hospitals NHS Foundation Trust. Members of the school of pharmacy's academic team began conversations with the director of pharmacy and his senior staff to explore potential work-based learning and clinical teaching of student pharmacists. An official partnership agreement was established that described how students would be taught dispensing and clinical checking in the hospital dispensary by a member of the pharmacy team who would be funded by the school but work in the hospital (a setting with high environment fidelity). Ten dispensary sessions, delivered 


\section{American Journal of Pharmaceutical Education 2019; 83 (7) Article 7106.}

over a 20-week period from September to April, were codesigned by the school's supervising academic, who was also a qualified pharmacist, and the hospital pharmacy technician. The three-hour sessions were framed by specific dispensing activities. The relevant processes and procedures involved using actual patient prescriptions, which had been anonymized and grouped to ensure students would learn about specific therapeutic areas within each session. The final dispensed and checked prescription was not for a real patient. Students were expected to engage and work with the JAC system (https://jac.co.uk/), an integrated electronic pharmacy management and stock control system, and become familiar with the traditional "medicine boxes on shelves," as well as the robotic dispensing approach for managing and dispensing medications (a setting with high equipment and psychological fidelity). Our approach was pedagogically informed by the evidence that high-fidelity clinical simulation provides a safe and supportive environment, which allows learners to develop skills and competence to enhance their performance without inflicting adverse clinical outcomes. $^{12}$

In October 2017, students received introductory lectures regarding patient confidentiality, standard operating procedures, and checking processes for prescription validity and legality. By the end of October, groups of four students were assigned three-hour sessions in the hospital dispensary every two weeks. From October to December 2017, students also attended a series of teaching sessions on the specifics of UK pharmacy law, specifically the Medicines Act 1968 and the Human Medicines Regulations 2012, which further consolidated laws concerning medicinal products for human use. ${ }^{13}$

Students were instructed to record their experiences during the dispensing sessions in their professional portfolios in the form of blog entries. Blogs are recognized as an information sharing technology that engages a dedicated readership in knowledge sharing, reflection, and debate. They have also been used to foster small virtual groupings of interested individuals to co-construct knowledge around a common topic in a community of practice. ${ }^{14}$ In associated reflection seminars, students were provided with instruction on how best to record a blog that would provide the basis for building a formal reflective account. Students in stage 2 were required to write a reflective account as a formative assessment. To accomplish this reflection, students were provided with instruction and encouraged to use experiences such as the dispensing sessions as an opportunity to reflect on practice, perspective, and understanding. To further support the dispensing sessions, students were required to attend small group review with academic staff on a biweekly basis. These tutorials were open for students to share their experiences and observations of their teaching and learning. The academic team used these encounters to discuss the student learning experience of the novel dispensing teaching and learning strategy. This was regarded as an opportunity for elaboration, where discourse can help learners to relate new information to existing knowledge, enhancing deeper learning, richer understanding, and better use of knowledge. ${ }^{15}$

As part of this study, content analysis was used to systematically and objectively explore students' experiences during the dispensing sessions as reported in their blog entries. Content analysis was used to interpret text data from a predominantly naturalistic paradigm. The conventional approach was adopted here, which aimed to inductively develop categories through immersion in the data allowing the insights to emerge. ${ }^{16}$ Blog entries from October 2017 to December 2017 were downloaded from the electronic professional portfolios of the 48 (total cohort) stage 2 students. An inductive approach was adopted in which blogs were openly coded, categories created, and abstractions formed so specific findings could be combined into a comprehensive overview of the student experience. ${ }^{17}$ Two researchers independently analyzed the blogs and discussed first impressions, thoughts, and their initial analysis. The two researchers then assigned derived codes to the data and sorted the coded data into categories. Where discrepancies in findings and abstractions occurred, a third researcher was consulted who provided consensus on the final categories. An advantage of using this approach is that information is gained directly from the participants rather than imposing a priori categories or theoretical perspectives. However, a challenge to this methodology is the limited ability to develop a complete understanding of the context, which reduces the credibility of the findings. ${ }^{16}$ Lincoln and Guba recommend conducting further activities, including peer debriefing, member-checking, triangulation, and persistent observation, as strategies to establish credibility. ${ }^{18}$

This study was submitted through the Newcastle University, Faculty of Medical Sciences electronic ethical review. This process deduced that full ethical review submission was not required because of the non-invasive research design and non-sensitive research question. However, all students were provided with a participant information sheet to explain the research study, and blogs were only obtained from those students who consented to participate (completed consent forms).

Lave and Wenger posit that a community of practice has an identity defined by a shared domain of interest and that membership in the community implies a commitment to the domain. ${ }^{10,11}$ In the blogs, students shared 


\section{American Journal of Pharmaceutical Education 2019; 83 (7) Article 7106.}

experiences of learning about the dispensing and checking process and procedures (the domain of interest) as they undertook the session activities. Many of the blog entries demonstrated an appreciation of the cognitive and mechanistic steps in assessing the validity, legality, and clinical appropriateness of the patient prescriptions.

Students who had recorded consecutive blogs articulated an increasing awareness of developing a personal cognitive checking and dispensing process to improve the safety and efficiency of their practice. There was a high proportion of students reflecting on mistakes they made in the dispensing sessions as they undertook the simulated exercises. Students mainly expressed feelings of frustration with themselves.

However, there was acknowledgement that although the teaching session was simulated, it felt very real, and students appreciated the opportunity to practice without threat or risk to patient safety. Students often reflected on their errors in relation to the potential consequences on patient care and safety, which appeared to increase their internal motivation to improve their practice.

A necessary component of a community of practice is that members of a specific domain interact and engage in shared activities, help each other, and share information with each other. They establish relationships that facilitate learning from each other. ${ }^{10,11}$ As students worked at their own pace, there were varying levels of completion of session activities. However, students demonstrated appreciation for the potential to learn from their peers in the session debrief, and to discuss their own performance within the group to further their understanding and address any knowledge gaps.

Many students also captured their observations of the working environment and team dynamic within the hospital pharmacy team. Students evidenced their realization of the roles and responsibilities of team members, which did not always correspond to their preconceptions. They were able to appreciate the interconnectedness of the elements of labor and therefore the collaborative community.

The third component for a community of practice is that members are practitioners. They develop a repertoire of resources including stories, helpful tools, experiences, and ways of handling problems. ${ }^{10,11}$ Students' blogs recorded experiences of becoming familiar with the terminology, language, physical resources, and technology that are all artifacts in the checking and dispensing procedures.

From the outset, the majority of students reported their experiences with orientating themselves physically within the dispensary environment, with many noting the surrounding activities and observing the aspects of the context to the working practice. Several students reflected on their future, where they pictured themselves working as a pharmacist in the hospital sector, where they would be problem solving, seeking information, and contributing to practice.

\section{RESULTS}

Students' electronic professional portfolios were accessed in January 2018, at the beginning of the second term. By this point in the academic year, the stage 2 students $(n=48)$ had attended four dispensing sessions and completed and entered 192 blogs in their portfolio. By January 10, 2018, 102 blogs (53.1\%) had been submitted by the consenting students $(n=48,100 \%$ of the stage 2 cohort), and each student had recorded at least one entry pertaining to a dispensing session. There was a general homogeneity in the types of observations and experiences captured in the student blogs. The codes generated by the two researchers reached saturation and were found to align to categories mapping to the three components of a community of practice: domain, community, and practice. An excerpt of illustrative quotes, derived codes, and categories has been included in Table 1. The findings from the three categories are explained below and illustrative student quotes are detailed in Appendix 1.

\section{DISCUSSION}

An actual hospital dispensary served as a highfidelity teaching environment for students to learn about the processes and procedures of medication dispensing and clinical checking. Findings affirm that students experience and perceive this teaching approach as having high environmental, equipment, and psychological fidelity. Co-facilitation and design of teaching sessions between a school-employed but hospitallocated pharmacy staff and institutional faculty members led to the development of educational activities that were realistic. Undertaking these sessions in the hospital dispensary allowed students to develop skills and knowledge of key resources, terminology, and technology. The reported student learning included the mechanistic processes of dispensing and checking relating to their task performance, eg, operating electronic systems, registering prescriptions, and generating labels. Students demonstrated development of professional understanding and identity through their described performed roles. This latter achievement was ameliorated by the immersive, realistic (ie, highfidelity) environment, which is a component of the new teaching and learning approach.

The two specific typologies, task and role performance, were also reported by Wallman and colleagues ${ }^{19}$ 


\section{American Journal of Pharmaceutical Education 2019; 83 (7) Article 7106.}

Table 1. Results of a Content Analysis of Student Pharmacist Blogs and Exemplar Quotes Regarding Their Experience While Undergoing High-Fidelity Clinical Training in Medication Dispensing and Checking

\begin{tabular}{|c|c|c|}
\hline Category & Codes & Student Quotes \\
\hline \multirow[t]{3}{*}{ Domain } & $\begin{array}{l}\text { Clinically checking } \\
\text { information }\end{array}$ & "I knew I had to check the appropriateness of the drug and the dose..." S32 \\
\hline & $\begin{array}{l}\text { Developing a } \\
\text { cognitive process for } \\
\text { checking }\end{array}$ & $\begin{array}{l}\text { "I had to go through some mental steps in the right order to make sure I } \\
\text { covered everything." S }\end{array}$ \\
\hline & $\begin{array}{l}\text { Technical process of } \\
\text { dispensing }\end{array}$ & $\begin{array}{l}\text { "After checking the prescription, it was about actually getting that medication } \\
\text { and preparing ready to give to a patient" S65 }\end{array}$ \\
\hline \multirow[t]{3}{*}{ Community } & Peer review & $\begin{array}{l}\text { "The group review allowed us to look at each other's work and see how other people } \\
\text { did it. . .like did they do it faster, or get less mistakes... and how they did it" S86 }\end{array}$ \\
\hline & Collaborative learning & $\begin{array}{l}\text { "We were giving each other tips, like to remember the short codes for doses, and } \\
\text { how to use some of the tabs on the system." S43 }\end{array}$ \\
\hline & $\begin{array}{l}\text { Comparing/benchmarking } \\
\text { performance }\end{array}$ & $\begin{array}{l}\text { "I knew I was rushing, but I felt I was much slower than everyone else. I think I was just } \\
\text { overthinking." S12 }\end{array}$ \\
\hline \multirow[t]{2}{*}{ Practice } & Using resources & $\begin{array}{l}\text { "You couldn't really do it without the BNF [British National Formulary], so I made } \\
\text { sure I had it or used the app." S45 }\end{array}$ \\
\hline & Using computer software & $\begin{array}{l}\text { "It was difficult to remember what buttons to press in the JAC system, but I knew I } \\
\text { just need to use it more." S76 }\end{array}$ \\
\hline
\end{tabular}

as student-reported learning outcomes from a six-month workplace learning experience. Authors also reported student perceptions of developing professional identity as they "learnt how to learn" in a professional setting. ${ }^{19}$ This resonated with the content of the recorded blogs, where students were adapting their ways of learning from the resources, equipment, and interactions within the workplace environment. The situated learning of the task and role performance can be considered to be organized and regulated by the social structure of the workplace environment. In fact, Lave argues that it is the increased appreciation of the social practice that organizes a workers' or learners' access to knowledge needed to sustain those practices. ${ }^{20}$ Applying this theory to our teaching strategy would mean that the workplace nature of the dispensing and checking processes and procedures was enhanced and informed by the immersive environment of the hospital dispensary. Valsiner refers to this as the co-construction of knowledge: where individuals will elect how they engage and what they construct from that engagement, while social practices are able to provide different levels of pressure for individuals to engage with particular knowledge. $^{21}$

There is a scarcity of research related to the instruction of clinical checking and dispensing in pharmacy education. MyDispense has been described as an innovative strategy to integrate the relevant knowledge, critical thinking, technical activities, communication skills, and values necessary for developing dispensing skills. ${ }^{4}$ Shin and colleagues describe the main learning objective that students achieved through MyDispense was that it allowed them to identify and gather relevant patientspecific information. Some authors continue to claim that MyDispense has a limited scope of simulation because it does not simulate hospital pharmacy practice or an authentic interaction with other health care providers and patients (low environmental fidelity). ${ }^{22}$ However, given the aforementioned benefits of the MyDispense software, it could be incorporated within the current teaching approach to supplement and consolidate learning in a live dispensary session.

The implementation of this approach to dispensing is facilitated in our particular situation, through the colocation of the hospital and the pharmacy school. Clearly, the availability of a high-fidelity environment where students can experience an actual pharmacy setting without compromising patient safety is key to this approach. Also, the amount of responsibility that students should be allowed to assume within the workplace is difficult to define given the legal and ethical requirements placed upon hospital pharmacists, who have overall responsibility for patients. Genuine peripheral participation is potentially difficult to achieve; however, this approach is the first step to developing a structure to allow students to learn dispensing and checking within a fully operational hospital dispensary (ie, using real prescriptions for actual patients). We would argue that this approach requires substantial financial support and commitment from the 


\section{American Journal of Pharmaceutical Education 2019; 83 (7) Article 7106.}

university and hospital involved, as well as thoughtful scheduling throughout the year to ensure that the pharmacy dispensary experience is scalable to accommodate a larger number of students.

This report provides valuable insight into how relationships with health care providers in clinical settings can be used to design novel educational opportunities that facilitate professional and cognitive knowledge, skill, and attitudinal development that would otherwise not be achievable in the classroom environment. Our study was limited to an inpatient hospital setting and thus is not generalizable to community-based environments. Also, we did not evaluate the impact of the situated learning on student performance on summative assessments by comparing that with student performance on summative assessments after learning the material in a low-fidelity classroom setting. However, because of the fundamental change in the teaching approach used, an appropriate assessment would have to be developed as it would be inappropriate to use the previously employed lower-fidelity assessment that was befitting the replaced classroom model.

\section{CONCLUSION}

Our study demonstrated how effective working relationships between a school of pharmacy and a teaching hospital can facilitate innovative teaching and learning experiences that are of added educational and developmental value to students. The high-fidelity training on medication dispensing and checking in a live hospital environment allowed students to learn within a community of practice. This situated education offers students a learning experience that is continuous, active, engaging, and identity forming, rather than solely focused on the mastery of a skill in a specific setting. This interaction will enable learners to progress toward full participation in the sociocultural practices of the professional pharmacy community and enable them to become a part of a community of practice.

\section{ACKNOWLEDGMENTS}

We would like to acknowledge Neil Watson who played a key role in establishing the partnership between the Trust and the University and informing the design of the student experience.

\section{REFERENCES}

1. General Pharmaceutical Council. Future pharmacists. Standards for the initial training and education of pharmacists. May 2011. GPhC. https://www.pharmacyregulation.org/sites/default/files/ document/gphc_future_pharmacists_may_2011.pdf. Accessed September 18, 2018.

2. Cheetham G, Chivers G. Professions, Competence and Informal Learning: The Nature of Professions and the Role of Informal Learning in Acquiring Professional Competence. Cheltenham: Edward Elgar; 2005.

3. Epstein RM, Hundert EM. Defining and assessing professional competence. JAMA. 2002;287(2):226-235.

4. McDowell J, Styles K, Sewell K, et al. A simulated learning environment for teaching medicine dispensing skills. Am J Pharm Educ. 2016;80(1):Article 11.

5. Sosabowski MH, Gard PR. Pharmacy education in the United Kingdom. Am J Pharm Educ. 2008;72(6):Article 130.

6. Rehmann A, Mitman R, Reynolds M. A Handbook of Flight Simulation Fidelity Requirements for Human Factors Research. Technical Report No. DOT/FAA/CT-TN95/46. Wright-Patterson AFB, OH: Crew Systems Ergonomics Information Analysis Center, 1995.

7. Beaubien JM, Baker DP. The use of simulation for training teamwork skills in health care: how low can you go? BMJ Qual Saf. 2004;13:i51-i56.

8. Hall K, Musing E, Miller DA, Tisdale JE. Experiential training for pharmacy students: time for a new approach. Can J Hosp Pharm. 2012;65(4):285-293.

9. Raelin JA. A model of work-based learning. Organization Science. 1997;8(6):563-578.

10. Lave J. Situating learning in communities of practice. Perspectives on Socially Shared Cognition. 1991;2:63-82.

11. Wenger E. Communities of Practice: Learning, Meaning, and Identity. New York: Cambridge. 1998.

12. Eng AJ, Namba JM, Box KW, et al. High-fidelity simulation training in advanced resuscitation for pharmacy residents. Am J Pharm Educ. 2014;78(3):Article 59.

13. Department of Health. Legislation covering medicines, Amending Legislation, Statutory Instruments: 2009/1164, 2010/ 1882. https://www.health-ni.gov.uk/articles/legislation-coveringmedicines\#toc-3. Accessed September 18, 2018.

14. Boulos MNK, Maramba I, Wheeler S. Wikis, blogs and podcasts: a new generation of web-based tools for virtual collaborative clinical practice and education. BMC Med Educ. 2006;6:41.

15. Harris KR, Alexander PA. Integrated, constructivist education: challenge and reality. Educ Psycol Rev. 1998;10:115-127.

16. Hsieh HF, Shannon SE. Three approaches to qualitative content analysis. Qual Health Res. 2005;15(9):1277-1288.

17. Elo S, Kyngas $\mathrm{H}$. The qualitative content analysis process. $J A d v$ Nursing. 2008; 62(1):107-115.

18. Lincoln YS, Guba EG. Naturalistic Inquiry. Sage; 1985. 19. Wallman A, Sporrong SK, Gustavsson M, Lindblad ÅK, Johansson M, Ring L. Swedish students' and preceptors' perceptions of what students learn in a six-month advanced pharmacy practice experience. Am J Pharm Educ. 2011;75(10):Article 197.

20. Lave J. The Culture of Acquisition and the Practice of Understanding. Situated Cognition: Social, Semiotic, and Psychological Perspectives. 1997:63-82.

21. Valsiner J. Culture and Human Development. London, Sage Publications; 2000.

22. Shin J, Tabatabai D, Boscardin C, Ferrone M, Brock T.

Integration of a community pharmacy simulation program into a therapeutics course. Am J Pharm Educ. 2018;82(1):Article 6189. 


\section{American Journal of Pharmaceutical Education 2019; 83 (7) Article 7106.}

Appendix 1. Categories Generated From Analysis of Student Pharmacists' Blogs and Illustrative Quotes Regarding Their Experience While Undergoing High-Fidelity Clinical Training in Medication Dispensing and Checking

Categories Student Quotes

Domain "I know that I have to check all the legalities on the prescription, from my law lectures, and also do all the checks of the drug in the BNF [British National Formulary], before I can use the system to make labels. Then I have to use the prescription, not the labels, to then select the correct medicine." S41

"I will try to develop a mental checklist of tasks that must be done with every prescription; I will be less likely to make these kinds of mistakes if I have a system to follow." S21

"I didn't like the fact that I have made so silly errors and overlooked some aspects of the work where minimal or no error is required. Looking back now at my mistakes, I have noted some common errors and how to avoid them." S33

"If this had really happened and it hadn't been spotted and checked with the prescriber, the patient could have had a very bad allergic reaction to the drug, and in the worst case scenario, they could have died as a result of it. This was a very important learning point for me, as it has helped me realise to a greater degree how important accurate checking of prescriptions is, as this could easily have been missed." S18

Community "During my time there, I got to witness the interactions between staff that were occurring and seeing the importance of this." S6

"Furthermore, I expected the dispensary room to be hectic and the work load to be a lot because it was in a hospital setting and on a Friday, however it was calm and work load seemed to be handled smoothly." S15

"Upon reflection I found that my expectations of what a hospital pharmacy was archaic. The pharmacists work on the wards and send their prescriptions to the dispensary meaning they are constantly patient facing, and the dispensing technicians were giving the responsibility of assembling the prescriptions." S47

"In our debriefing session my colleagues and I also discussed how some parents would prefer using a syringe rather than a spoon (especially with young children) because it may be difficult otherwise to get the child to take their required medicine." S18

"Later on I discovered in our debriefing session that my colleagues felt the same way, which was reassuring because I realised that everyone was in a similar position to me in the learning process." S26

Practice "However, once I had received the tour I felt a lot more comfortable as I felt I knew my surroundings a lot more and had become more familiar with the task I was about to carry out. It was also interesting to see a live dispensary in action whilst I was working" S15

“... it was a good experience and I'm excited to learn more working within a live dispensary with real work occurring around me so whilst I learn I can also see what happens in the normal day to day of a hospital dispensary." S4

"I found myself making mistakes which were not made in the first week, things such as forgetting to request the robot to dispense a box as opposed to a single drug." S14

"I felt that I quickly became accustomed to using the JAC system [electronic platform used in dispensing medications] to generate labels and was therefore able to get the robot to dispense the different medications. However, at the time I felt I wasn't fully comfortable with using the BNF to generate counselling points that I would give to the patient." S16

"I found the experience very enjoyable and started to visualise myself in a working pharmacy environment" S34

"This was very beneficial and interesting for me as it gave me an opportunity to see a running hospital dispensary, allowing me to have a taste of what working in hospital pharmacy would be like." S6 